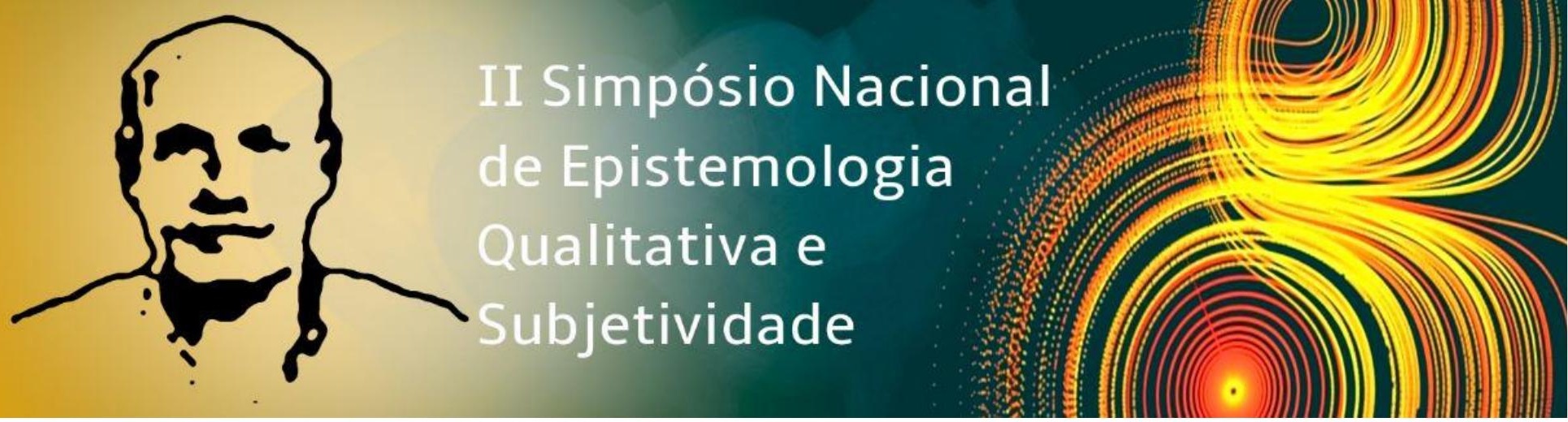

Eixo temático:

2. Epistemologia Qualitativa e metodologia construtivo-interpretativa: discussões conceituais e relações com outras perspectivas epistemológicas e metodológicas

\title{
Pesquisando a dimensão subjetiva da realidade: aproximações com a Epistemologia Qualitativa e a metodologia construtivo-interpretativa
}

Ana Mercês Bahia Bock - Pontifícia Universidade Católica de São Paulo (PUC-SP), anabbock@gmail.com

Rita de Cássia Mitleg Kulnig - Doutora pelo Programa de Pós-Graduação em Educação: Psicologia da Educação (PUC-SP), rdecassia@ hotmail.com

Luane Neves Santos - Universidade Federal do Recôncavo da Bahia (UFRB), luanepsi@yahoo.com.br

\section{Resumo}

O presente trabalho se organiza como uma reflexão de caráter epistemológico, teórico e metodológico acerca das aproximações que o grupo de pesquisa DSigual ${ }^{1}$ tem produzido com a Epistemologia Qualitativa e a metodologia construtivo-interpretativa, a partir da Psicologia Sócio Histórica. Considerada uma categoria basilar, a dimensão subjetiva da realidade questiona a dicotomia indivíduo-sociedade e permite-nos dialogar com diversos fenômenos da vida social, considerando que as expressões objetivas e materiais dos mesmos possuem uma dimensão constituída por elementos de natureza simbólica ou psicológica. Em nossas pesquisas, o uso desta categoria tem por objetivo apreender os fenômenos em sua totalidade, a partir do seu movimento, suas contradições, sua historicidade, sendo o campo das significações privilegiado para tal processo. Em termos de estratégia de análise, esse caminho vem sendo construído por meio dos núcleos de significação (AGUIAR; OZELLA, 2006, 2013; AGUIAR;

${ }^{1}$ O Grupo de Pesquisa Dimensão subjetiva da desigualdade social: suas diversas expressões - Dsigual, certificado pela Pontifícia Universidade Católica de São Paulo e cadastrado no CNPq, tem pesquisado a dimensão subjetiva da desigualdade em vários campos e temas: saúde, políticas públicas, educação, trabalho. Disponível em http://dgp.cnpq.br/dgp/espelhogrupo/3143688529030231 


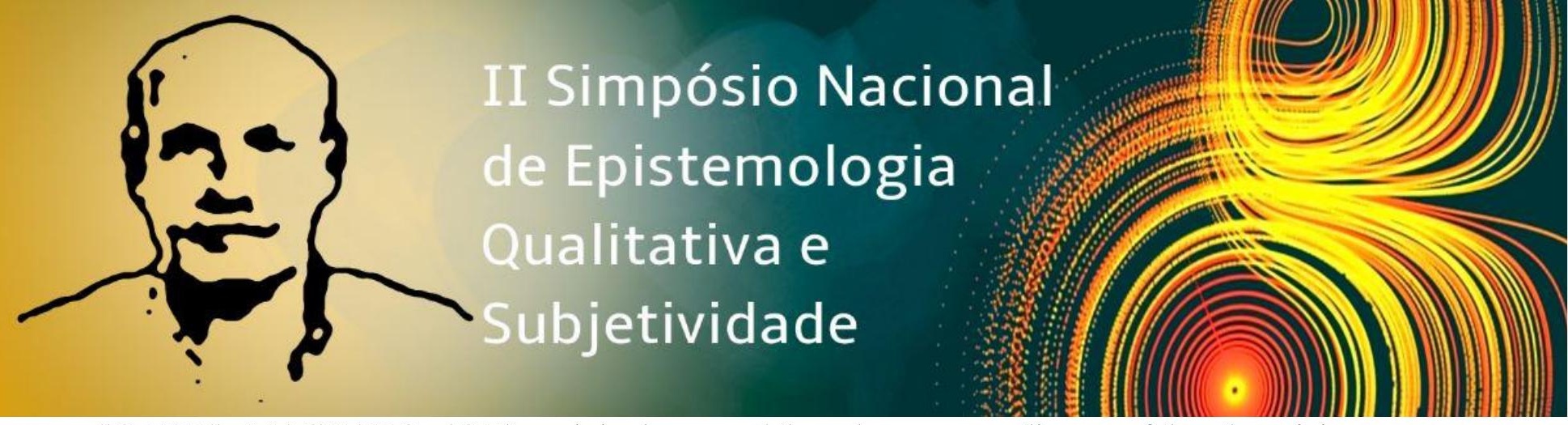

SOARES; MACHADO, 2015), originalmente elaborados para analisar as falas de sujeitos obtidas por meio de entrevistas e/ou conversações individuais, este recurso vem sendo ampliado para a análise de sujeitos em grupo (ARANHA, 2015; PENTEADO, 2017; PERDIGÃO, 2019; KULNIG, 2019), bem como das "falas" dos sujeitos expressas por meio da linguagem escrita (MELSERT, 2013; KULNIG, 2019). A forma como construímos nossas pesquisas dialoga com a Epistemologia Qualitativa de Rey (2005a; 2005b; 2009) em vários aspectos. Primeiramente, concordamos que o pesquisador está diante de um caminho singular ao empreender o desenvolvimento de uma pesquisa, e que o planejamento desta exerce muito mais o papel de avaliar a representação que este tem sobre o que irá estudar e a forma como pretende acessar os sujeitos a serem analisados do que uma sequência rígida de etapas a serem seguidas. Um segundo aspecto é o reconhecimento da singularidade como fonte de conhecimento potente. Embasamos este entendimento nas explicações de Rey (2005a) que compreende o sujeito como forma única e diferenciada de constituição subjetiva, atribuindo legitimidade ao conhecimento científico produzido não pela quantidade de sujeitos estudados, e sim pela qualidade da expressão do sujeito. Um outro aspecto é a construção do cenário social de investigação, isto é, o contexto que se produz para implicar tanto os participantes quanto o pesquisador no processo de realização da pesquisa. Também consideramos as técnicas e os instrumentos utilizados como indutores de informações, como uma via para estimular e enriquecer as oportunidades de expressão, de estimulação da produção de sentidos dos sujeitos que participam do processo de pesquisa e não como um fim em si mesmo. Nesse sentido, a focalização de um fenômeno particular, levando em conta seu contexto e suas múltiplas dimensões, poderá requerer do pesquisador estratégias diferenciadas para dele se aproximar (como conversações, análise documental, construção do diário de campo), de modo a produzir informações que o permitam ir além da aparência, favorecendo uma visão de totalidade.

Palavras chave: dimensão subjetiva, psicologia sócio histórica, metodologia construtivointerpretativa

\section{Referências}


